\title{
Arquitetura da tensão em tempos de repressão \\ uma interpretação do samba "Roendo as unhas", de Paulinho da Viola
}

\author{
Eduardo de Lima Visconti ${ }^{1}$
}

\begin{abstract}
Resumo
Paulinho da Viola se consagrou como um dos protagonistas do mundo do samba na década de 1970. Em tempos de "chumbo", a canção "Roendo as unhas", lançada no ano de 1973, parece introjetar uma "semântica da repressão" em sua forma musical. A partir da análise desse samba verifica-se que dois recursos - o intervalo musical do trítono e um princípio de circularidade - atravessam todos os componentes musicais (melodia, harmonia, arranjo e base rítmica), conferindo à letra uma potência de tensão onipresente na organização estrutural da canção. O artigo pretende compreender o processo pelo qual o artista alcançou uma compatibilidade entre estruturas musicais e letra, resultando numa obra que condensa, em seu material estético, uma experiência que se refere ao andamento histórico do período².
\end{abstract}

\section{Palavras-chave}

Paulinho da Viola, "Roendo as unhas", MPB, samba.

Recebido em 28 de janeiro de 2014

Aprovado em 21 de maio de 2014

VISCONTI, Eduardo de Lima. Arquitetura da tensão em tempos de repressão: uma interpretação do samba "Roendo as unhas", de Paulinho da Viola. Revista do Instituto de Estudos Brasileiros, Brasil, n. 59, p. 129-148, dez. 2014. DOI: http://dx.doi.org/10.11606/issn.2316-901X.v0i59p129-148

1 Universidade Federal de Pernambuco (UFPE, Recife, Pernambuco, Brasil).

2 Este artigo faz parte do projeto de pesquisa de pós-doutorado sobre sonoridades do samba da década de 1970 , realizado com bolsa de pós-doutorado júnior do CNPq e supervisão do Prof. Dr. Walter Garcia da Silveira Junior (IEB-USP). 


\title{
Architecture of Tension in Times of Repression An Interpretation of the Samba "Roendo as unhas", by Paulinho da Viola
}

\author{
Eduardo de Lima Visconti
}

\begin{abstract}
Paulinho da Viola is acclaimed as one of the protagonists of the world of samba in the 1970s. In times of violent repression, the song "Roendo as unhas", launched in 1973, seems to internalize "semantics of repression" in its musical form. From the analysis of that samba it can be observed that two features - the musical interval of the tritone and a principle of circularity - go across all musical components (melody, harmony, arrangement and rhythmic base), conferring to the lyrics a force of omnipresent tension in the structural organization of the song. The article aims to understand the process by which the artist has achieved compatibility between musical structures and lyrics, resulting in a work that condenses, on its aesthetical material, an experience that refers to the historical course of the period.
\end{abstract}

Keywords

Paulinho da Viola, "Roendo as unhas", MPB, samba. 


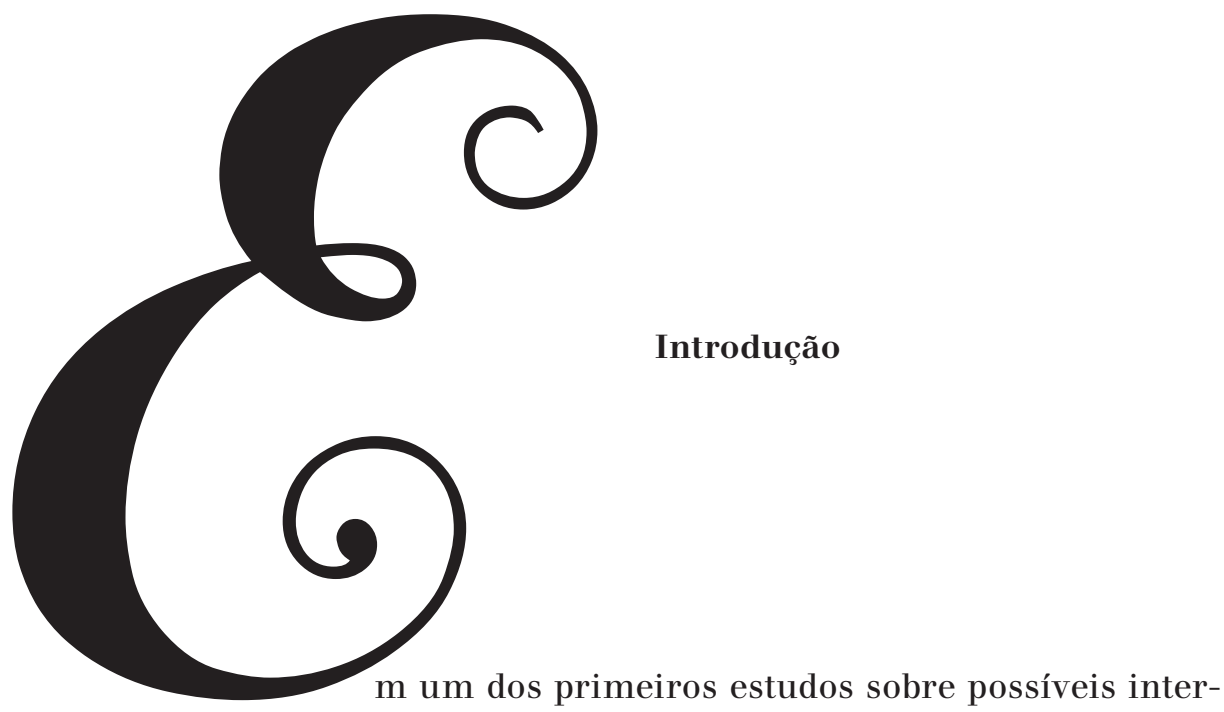
penetrações entre ideologia e canção popular brasileira, em especial, num conjunto de composições de Chico Buarque, Adélia Bezerra de Menezes jogou luz sobre a materialização do conteúdo político na poesia desse compositor ${ }^{3}$. De acordo com a pesquisadora, parte da produção de Chico compreendida entre uma das fases mais repressivas da ditadura militar no Brasil (1970-1973) carrega em sua forma uma "semântica e sintaxe da repressão", ou seja, verificou-se em que medida a matéria da repressão se transformou em elemento estrutural nessas "canções de protesto". Por ora, cabe lembrar aqui que “Construção”, lançada em 1971, faz parte dessa análise.

Apresentado o tema inicial, passo para o seu desenvolvimento, sem conexão direta com o trabalho de Adélia Bezerra de Menezes mencionado, mas também aplicando a classificação de "canção de protesto" à música "Sinal Fechado" (1969), de Paulinho da Viola, que obteve sucesso comercial no mesmo período. Para Eduardo Granja Coutinho, essa canção revela uma maior liberdade estética em contraponto a músicas como "Foi um rio que passou em minha vida", dentre outras, identificadas mais ao universo do samba. Isso seria decorrente de aproximações com a estética tropicalista e de estudos da obra violonística de Villa-Lobos. Nas palavras do próprio sambista, "Sinal Fechado é conseqüência do contato que tive com músicos mais recentes - Caetano, Chico, Gil, Edu das diversas correntes da música popular brasileira, desde 1964, quando me meti nesse negócio". ${ }^{4}$

3 MENEZES. Adélia Bezerra de. Desenho mágico: poesia e política em Chico Buarque. São Paulo: Ateliê Editorial, 2000.

4 Paulinho da Viola apud Coutinho. Ver COUTINHO, Eduardo Granja. Velhas histórias, memórias futuras. Rio de Janeiro: Editora UFRJ, 2011. p. 130. 
Todavia, o comentário de Coutinho também propõe uma interpretação de cunho político-ideológico à música do sambista, especificamente ao classificá-la como uma nova modalidade de canção de protesto, muito por fugir à temática nacional-popular centrada nos morros ou no sertão tão comum à época. Em outras palavras, nota-se nessa composição elementos distintos aos da produção de Paulinho da Viola do final dos anos de 1960 e início de 1970. Nessa perspectiva, o autor menciona ainda o samba "Roendo as unhas" (1973). Vale a pena conferir sua análise:

Outros sambas, como "Roendo as unhas" (música sem tônica, nem dominante, tematizando a própria relação do compositor com sua música - Meu samba não se importa se eu não faço rima/ Se pego na viola e ela desafina), demonstram a incorporação por Paulinho da Viola de influências e informações adquiridas no convívio com os novos compositores da MPB e em aulas teóricas. ${ }^{5}$

De acordo com o pesquisador, "Sinal Fechado" e "Roendo as unhas" apontavam para outra direção estética na trajetória do sambista da Portela. Tal argumento já tinha sido levantado por Tárik de Souza. O jornalista descreve esse processo como uma transformação do samba, evidenciando aspectos incomuns ao gênero como "uma sessão de improvisos dissonantes" em "Roendo as Unhas" e um "suspense de cordas coerente com o enredo urbano no exemplo de 'Sinal Fechado". ${ }^{6}$

Seguimos agora para texto publicado no site oficial de Paulinho da Viola intitulado "A experimentação", cujo conteúdo aborda os procedimentos musicais adotados no samba "Roendo as unhas". Reproduzo os aspectos cruciais:

Em sua forma nada é fixo, não há chão, há apenas os deslocamentos. É impossível determinar a nota dominante, ela não existe. O que vemos é uma sucessão de momentos que se envolvem e criam um ciclo de inúmeras possibilidades. O sambista ganha um olhar profundo, filosofa sobre sua relação com a música e caminha pelas ruas com sua "flor nenhuma". A angústia de um momento de transformação da nossa história não poderia estar melhor representada. ${ }^{7}$

5 Idem, Ibidem, p. 128.

6 SOUZA. Tárik de. Paulinho da Viola: A revolução sem hecatombes. In: O som nosso de cada dia. Porto Alegre: L\&PM, 1983, p. 145-146.

7 Disponível em: http://www.paulinhodaviola.com.br. Acesso em: set. 201z. Não há créditos no site sobre a autoria do texto. 
Percebe-se, até aqui, que algumas questões levantadas em sentidos genéricos evidenciam, sem elaborar as devidas conexões, pistas do estranhamento presente em "Roendo as unhas". Quando o autor diz sobre a impossibilidade de determinar a nota dominante, talvez queira apontar para a ausência da nota fundamental da escala de Fá menor, em cuja tonalidade se estrutura a melodia, como nota de repouso. Quanto ao "ciclo de inúmeras possibilidades", possivelmente esteja se referindo à progressão harmônica cíclica, onde não há a resolução na tônica, que, por outro lado, impulsiona, como veremos adiante, as improvisações dissonantes. Daí se forma a ideia de um conjunto de práticas não-usuais para uma composição, cujo gênero é samba. Cabe lembrar que uma das características musicais desse gênero é a relação entre tensão (dominante) e repouso (tônica), procedimento básico que rege a harmonia da música tonal. No que tange às improvisações de novas melodias, raramente elas se fazem presentes no repertório de samba, pelo menos na sua forma-canção.

Uma aproximação possível para tentar explicar alguns procedimentos que possam ter servido de referência para Paulinho da Viola na feitura do samba analisado remonta a um período da sua carreira em que o artista se dedicou a estudos formais de música, primeiramente como aluno de Esther Scliar, e depois, no Instituto Villa-Lobos, no Rio de Janeiro $^{8}$. A dificuldade em evitar "que tudo acabe em samba" (como diz o célebre ditado popular) fica claro no depoimento do músico sobre o seu aprendizado:

Você sabe que eu fiz uma prova no Villa-Lobos, de composição, sobre o sistema serial e tirei 10. Eu fiz uma composição exatamente com os intervalos, respeitando o sistema, porque aquilo é terrível, né, e não pode lembrar tonalidade no encadeamento, é uma outra coisa, uma coisa mais árida. Você sabe que eu fiz, a professora não gostou da minha composição. Sabe por quê? Do ponto de vista técnico estava correta, mas ela não gostou porque achou que estava assim um pouco... brejeiro. ${ }^{9}$

8 Na década de 1960 o sambista estudou análise musical com a compositora e regente Esther Scliar, que havia sido aluna de Koellreutter, um dos introdutores da linguagem dodecafônica no Brasil. Anos mais tarde, teve aulas durante dois anos (1970 e 1971) no curso de música do Instituto Villa-Lobos. Ver COUTINHO, Eduardo Granja. Velhas histórias, memórias futuras, p. 170.

9 BOZETTI, Roberto. O universo ou o Infinito, desde o samba. Revista Brasileira de Estudos da Canção (RBEC). Natal, n. 3, p. 17-18, jan-jun 2013. Disponível em: http:// www.rbec.ect.ufrn.br/index.php/RBEC,_n.3,_jan-jun_2013. Acesso em: set. 2013. 
Tem-se aí um ponto importante que pode contribuir para nossa análise, sobretudo no que tange à organização dos elementos de "Roendo as unhas". Em linhas gerais, há o que chamo de dois princípios ordenadores que atravessam a gravação do início ao fim. São eles: a presença do trítono $^{10}$, intervalo musical de $4^{\mathrm{a}}$ aumentada ou $5^{\mathrm{a}}$ diminuta, símbolo do sistema tonal, que aparece insistentemente na harmonia, na melodia e no arranjo; e a noção de circularidade ocasionada pela repetição da métrica da letra, da melodia, do conteúdo harmônico, das práticas improvisatórias e da normatização do ritmo da base. Nota-se que devido a essas duas referências estruturais pode-se inferir que existe um equilíbrio entre harmonia, canto (melodia e letra) e arranjo. Dito de outra maneira, é como se cada componente da canção tivesse a mesma importância e, ao mesmo tempo, certa independência; quando articulados conjuntamente, percebem-se graus maiores de compatibilidade e adequação potencializando a verossimilhança ${ }^{11}$ e eficácia ${ }^{12}$ da canção. Cabe então supor que o contato do sambista com o rigor construtivista verificado em algumas linguagens musicais do século XX, como a técnica serial, talvez tenha contribuído para arquitetar a geometria de equivalência entre os

10 Como argumentarei ao longo do texto, a escolha deste intervalo, salvo grande equívoco, não aparenta ser aleatória ou inconsciente. Até porque, em 1978, o sambista utilizou o trítono para reforçar a parte principal do samba "Coração Leviano". Note-se que na sua melodia uma das notas do trítono do acorde diminuto potencializa o sofrimento expresso na letra (Ah! coração leviano). Ver TROTTA, Felipe C. Paulinho da Viola e o mundo do samba. 2001. 156 f.. Dissertação (Mestrado em música). CLA, Unirio, 2001, p. 115.

11 Em estudo sobre os três elementos do romance, a saber: enredo, personagens e "ideias" Antonio Candido elege a construção estrutural como responsável pela vitalidade e eficácia do romance. A verdade da personagem depende da função que esta exerce na estrutura do problema de organização interna. Portanto, a verossimilhança é alcançada à medida que o critério estético da organização interna, coerente e convencionalizado, representa o real partindo da unificação do fragmentário pela organização do contexto. Na medida do possível, aplico essa noção a "Roendo as unhas", sendo os graus de compatibilidade entre os elementos - melodia (altura e ritmo), letra, harmonia e arranjo - fatores decisivos para se chegar à consistência estética da canção; em outros termos, à verossimilhança, talvez, alcançada pelo compositor. Ver CANDIDO, Antonio. A personagem do romance. In: . A personagem de Ficção. São Paulo: Perspectiva, 2011.

12 Luiz Tatit trata da eficácia da canção a partir da adequação e compatibilidade entre os componentes melódicos e linguísticos, sendo o arranjo um elemento que pode contribuir nesse processo. O pesquisador fala ainda que essa articulação está vinculada à persuasão do ouvinte e, por conseqüência, à eficácia da comunicação das canções aos seus destinatários. Ver TATIT, Luiz. A canção: eficácia e encanto. São Paulo: Atual, 1986. 
componentes dessa composição, chegando ao ponto em que o reconhecimento da canção pode acontecer apenas pela audição de cada elemento isolado ${ }^{13}$.

\section{Dimensões subjetivas: desilusão e tragédia}

"Roendo as unhas" faz parte do disco Nervos de Aço, lançado pela gravadora EMI/Odeon no ano de 1973. Nesse fonograma há um total de dez músicas, sendo metade de autoria de Paulinho da Viola, e a outra, de compositores como Lupicínio Rodrigues, que dá título ao disco, Wilson Batista, Cartola, Chico Buarque, dentre outros. Um dos eixos centrais é o "samba da desilusão" 14 que norteia boa parte das dez gravações, sobretudo as composições autorais.

Um dos fundamentos que dá contundência ao significado dessa desilusão é o excelente texto de Nuno Ramos sobre Paulinho da Viola ${ }^{15}$. O artista plástico toca num ponto pouco discutido sobre a obra do sambista, especificamente sobre o caráter trágico e sóbrio das suas canções sintetizados na máxima: "Riso é riso e choro é choro. Mais choro do que riso". Ramos descreve o músico como pertencente a um grupo de sambistas que se esquivam do sentido genérico do samba malandro, engendrado pela dualidade entre trabalho e ócio. Nesse, o trabalho miserável se impôs ou simplesmente se ausentou, isto é, seria a versão "do desempregado ou de quem se presta a sub-empregos, de quem não soube ou não pôde ou não quis dar um jeito". ${ }^{16}$ Essa falta de dualidade traz uma mudança lírica profunda que, nas palavras do autor, se materializa numa canção que entristece e "se aquieta, perdendo velocidade e ginga". Cartola e Nelson

13 "Roendo as unhas" caminha na contramão do modelo de análise proposto por Luiz Tatit, que estuda a imbricação da letra e melodia como componente primordial para o reconhecimento da canção popular brasileira. Não se trata de negar o trabalho pioneiro e consistente desse pesquisador, mas de apontar um exemplo que foge a seu modelo de análise.

14 Tomo emprestada a ideia de Manoel Dourado Bastos que caracteriza essa forma de samba como representativa da estética de Paulinho da Viola. Ver BASTOS, Manoel Dourado. Notas de testemunho e recalque: uma experiência musical dos traumas sociais brasileiros em Paulinho da Viola e Chico Buarque (de meados da década de 1960 a meados da década de 1970). 2009. 282 f. Tese (Doutorado em História). Faculdade de Ciência e Letras de Assis, Unesp, 2oog, p.136.

15 RAMOS, Nuno. Ao redor de Paulinho da Viola. In: . Ensaio geral: projetos, roteiros, ensaios, memórias. São Paulo: Globo, 2007.

16 Idem, Ibidem, p. 85 . 
Cavaquinho são os pólos deste estilo de samba, sendo que a obra do segundo é entrecortada pela temática da morte, acentuando sobremaneira esse caráter trágico.

Voltando a "Roendo as unhas", considera-se que ela é uma amostra contundente da desilusão trágica de um dos tempos mais repressivos da nossa história, incorporando essa "semântica da repressão" em sua forma musical. Resta saber, como veremos abaixo, em que medida se dá esse processo.

\section{Dimensões objetivas: a gravação ${ }^{17}$}

De acordo com a pesquisadora Maria Luiza Kfouri ${ }^{18}$, os arranjadores que participaram do álbum foram: Maestro Gaya, Nicolino Cópia (Copinha), Cristovão Bastos, Nelson Martins dos Santos (Nelsinho) e Paulinho da Viola, embora não estejam discriminados em cada faixa.

A instrumentação tocada em "Roendo as unhas" é violão, piano, trombone, flauta, baixo elétrico e percussão. O primeiro elemento da música que já destoa e caminha na contramão da maioria das composições do sambista é a base harmônica tocada ao violão (Figura 1).

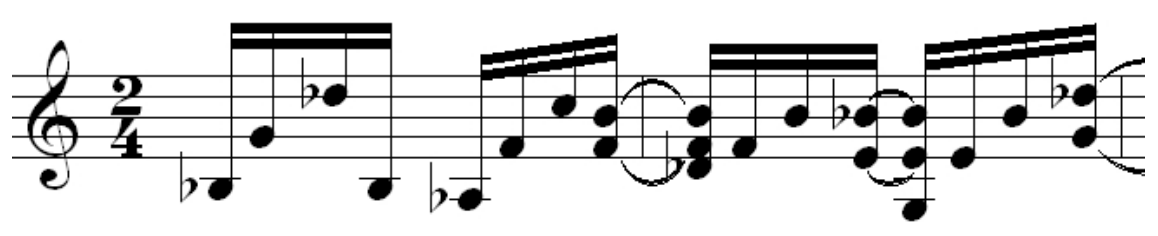

Figura 1: Levada de violão de "Roendo as unhas".

Executada sobre quatro acordes principais com ausência de suas quintas (Bbm6 / Ab6 / Db7 / G ${ }^{\circ}$ ), essa progressão harmônica se repete durante toda a gravação com poucas variações. O eixo norteador de ligação entre cada estrutura é o intervalo de quinta diminuta/quarta aumentada ${ }^{19}$, o já citado trítono, e que é vinculado a um recurso de tensão na prática musical. Nesse caso, além de compor os acordes de Bbm6, Db7

17 VIOLA, Paulinho da Viola. Roendo as unhas. Nervos de Aço (LP). EMI/Odeon, 1973.

18 Disponível em: http://Www.discosdobrasil.com.br. Acesso em: mar. 2013.

19 À exceção do acorde de Ab6. 
e $\mathrm{G}^{\circ}$ esse intervalo também aparece entre as fundamentais do penúltimo acorde (Db7) e do último $\left(\mathrm{G}^{\circ}\right)$.

Em relação à tonalidade da música, após transcrição conjunta da melodia e harmonia, presume-se que a seqüência esteja em Fá menor. Segue uma análise de cada acorde, tendo como referência a harmonia funcional aplicada à música popular:

Bbm6 - IVm (Subdominante menor)

Ab6 - bIII (Tônica anti-relativa)

$\mathrm{Db} 7-\mathrm{SubV}$

$\mathrm{G}^{\mathrm{o}}-\mathrm{II}^{\mathrm{o}}$ (Dominante - funciona como inversão do acorde de C7b9)

Todavia, o final interrompido da progressão no acorde de $\mathrm{G}^{0}$ revela um plano tonal que não se concretiza, pois não há o aparecimento do acorde com função tônica (Fm - Im) ao final da sequência. Tendo em vista que o tonalismo se configura a partir da relação de tensão e repouso, na progressão analisada, observa-se apenas a utilização da primeira característica.

Outro recurso notável na base é a disposição quase cromática na condução das vozes, principalmente as fundamentais dos acordes (refiro-me às notas Sib, Láb e Sol). A maneira como acontece a mudança dessas estruturas no violão remete a uma das técnicas de acompanhamento de João Gilberto, sobretudo no tocante à passagem entre alguns acordes, onde, através de pequenos ajustes, os desenhos de acordes vão se modificando e adquirindo diferentes funções harmônicas, revelando, assim, novos sons através de um mínimo esforço da mão esquerda.

Em termos de função harmônica, essa progressão apresenta-se distinta de grande parte dos sambas do músico, muitos deles compostos sobre um único centro tonal e com cadências comuns a outras composições do gênero ${ }^{20}$. Percebe-se um tratamento concentrado numa progressão circular, onde só notamos o início e seu fim devido à organização dos motivos da melodia, postos no espaço de dois compassos cada. Noutras palavras, há uma suspensão da resolução harmônica, o que contribui para concentrar a tensão que o trítono encerra. Como se fosse necessário comprimir, para que a angústia se revelasse com maior densidade e permanência.

Felipe Trotta faz uma sugestão inovadora sobre a possibilidade da conexão de determinados sentidos expressos na letra com a narrativa

20 TROTTA, Felipe C. Paulinho da Viola e o mundo do samba. 
harmônica no repertório do samba, sem a mediação da melodia. Em nosso exemplo, tudo sinaliza para essa prática, isto é, a tensão instaurada pelo sentido da letra parece orientar a base e vice-versa. Retomo a ideia de que os componentes desta canção funcionam de maneira independente, possibilitando, assim, esta combinação.

A repetição da base é reforçada com a antecipação (em semicolcheia) de cada acorde anterior ao primeiro e segundo tempos de cada compasso (exceto no acorde de Ab6), que cria, juntamente com um instrumento de percussão que acentua todos os tempos fortes, um ostinato rítmico, emergindo uma sensação de tensão e imobilidade. Percebe-se uma ideia de aparente equilíbrio e circularidade na base rítmica, visto que os dois tempos do compasso são normatizados com o ataque regular da percussão ${ }^{21}$.

Na introdução ao primeiro verso, Paulinho cantarola a vogal ô sobre a nota de Réb a qual, sobreposta à base, constrói um intervalo, mais uma vez, de quinta diminuta (se for considerado que, mesmo sem a resolução da cadência, o último acorde possui a nota sol em sua fundamental). Nesse momento, aparece a flauta improvisando algumas apojaturas sobre as notas de Láb ( $9^{\mathrm{a}}$ menor) e Réb ( $5^{\mathrm{a}}$ diminuta) e o trombone toca a nota Fá ( $7^{\mathrm{a}}$ menor), o que aumenta gradativamente o campo de tensão para a entrada da melodia/letra (Figura 2):

21 A regularização dos tempos dos compassos foi uma das inovações trazidas pela batida bossa nova de João Gilberto. O acento regular é garantido pelo desenho rítmico do bordão do violão em semínimas, caindo exatamente na cabeça de cada tempo do compasso de 2/4 de maneira uniforme. Em outras palavras, quando os bordões são tocados com igual intensidade na cabeça de dois tempos, nega-se a marcação do surdo, que, ao acentuar a cabeça do segundo tempo, convida à dança. Ver GARCIA, Walter. Bim Bom: a contradição sem conflitos de João Gilberto. São Paulo: Paz e Terra, 1999. A base percussiva da canção de Paulinho, na minha percepção, parece igualar os acentos rítmicos, desatando a articulação entre samba e dança, tão cara a esse gènero. 


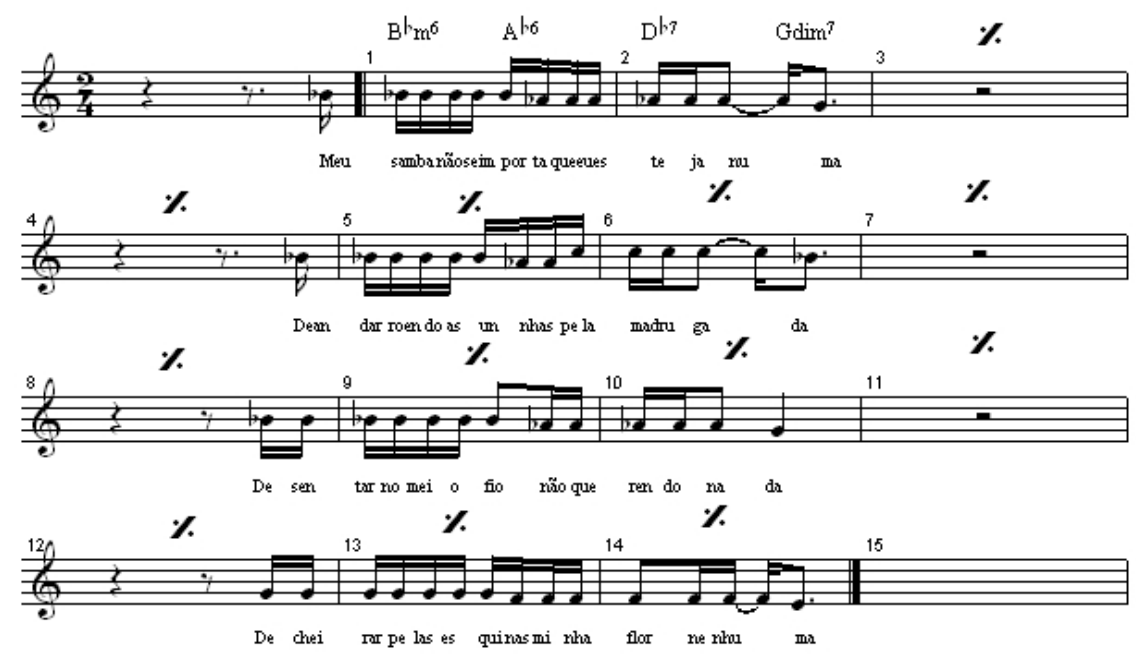

Figura 2: Melodia/Letra e harmonia da primeira estrofe de "Roendo as unhas". ${ }^{22}$

Abaixo, a letra correspondente à segunda e à terceira estrofes:

Meu samba não se importa se eu não faço rima

Se pego na viola e ela desafina

Meu samba não se importa se eu não tenho amor

Se dou meu coração assim sem disciplina

Meu samba não se importa se desapareço

Se digo uma mentira sem me arrepender

Quando entro numa boa ele vem comigo

E fica desse jeito se eu me entristecer

A melodia da música está construída sob a escala de Fá menor ${ }^{23}$ em movimento predominantemente descendente, inicia-se pelo quarto grau da escala (Sib), passa por outras notas, e termina no sétimo grau (Mi). Observa-se que em nenhum momento a fundamental da escala é alcançada como nota de repouso, similarmente à ausência do acorde de resolução (tônica) no plano harmônico. Pode-se dizer, então, que a não-resolução da melodia e da harmonia no primeiro grau é um dos recursos principais que engendra a tensão percebida na gravação.

22 Embora haja pequenas variações melódicas nas outras estrofes, optou-se apenas pela transcrição da primeira estrofe como amostra da relação entre letra e melodia. A escrita da partitura foi feita com acidentes ocorrentes nas notas.

23 Considera-se que seja a escala de Fá menor harmônica, porém a ausência do sexto grau da escala na melodia relativiza essa constatação. 
Outro aspecto relevante é a divisão rítmica da melodia, que se mantêm constante com pequenas variações; esse recurso aprofunda a noção de circularidade e repetição provenientes da base ritmo-harmônica (violão, baixo e percussão). Nota-se uma confluência entre o desenho da melodia e sua tessitura, reforçando o sentido de desamparo do narrador expresso na letra, isto é, do terceiro ao quarto verso (Figura 2) há um movimento descendente das notas em relação ao grave, repousando na nota Mi (c.14), que consiste na nota mais grave da tessitura inteira da música. Todavia, um dos pontos cardeais para nosso problema está condensado nesta estrofe, localizado na distância entre a primeira nota da melodia (Sib), no primeiro compasso, com a última (Mi), no compasso 14 , reiterando, novamente, a arquitetura de uma $5^{\text {a }}$ diminuta.

Na verificação entre alguns elos entre melodia e letra (composta por três estrofes com quatro versos cada uma) e sua estrutura musical, percebe-se um entrelaçamento entre canto e fala que aprofundam, em diferentes níveis, a tensão recorrente na composição. No que tange à relação de adequação entre letra e melodia, essa canção pode ser compreendida dentro do processo de figurativização, proposto por Luiz Tatit. Nesse conceito, "captamos a voz que fala no interior da voz que canta”, ou seja, há uma intimidade vital entre melodia e oralidade, que no plano melódico se traduz em poucos saltos, à base de graus conjuntos e $\operatorname{cromatismos}^{24}$. Esse processo parece ser determinante na acentuação das noções de repetição, circularidade e tensão que, no conjunto da peça, potencializam o sentido de desespero.

A relação visceral entre fala e canto na canção pode ainda ser observada se confrontarmos o ritmo presente na metrificação da letra com o ritmo da melodia ${ }^{25}$, daí chegamos a uma construção inusitada. À primeira vista, "Roendo as unhas" possui três estrofes com quatro versos em cada, sendo que parte significativa da metrificação é composta por versos dodecassílabos. Sabe-se que os poetas parnasianos abusaram desse estilo de versificação, o que talvez fundamente uma possível aproximação entre a estética parnasiana e as letras de Cartola, Nelson Cavaquinho e Paulinho da Viola. Olhemos o primeiro verso da canção:

24. TATIT, Luiz. O cancionista: composições de canções no Brasil. São Paulo: Edusp, 1996, p. 9-27.

25 Com o intuito tanto de aferir as conexões entre a linguagem oral e a canção, como de verificar a experiência histórica sedimentada no samba ora investigado, inspiro-me na proposta de Walter Garcia de "Um novo instrumento teórico para a análise do ritmo do canto". GARCIA, Walter. Melancolias, Mercadorias: Dorival Caymmi, Chico Buarque, o Pregão de Rua e a Canção Popular-Comercial no Brasil. Cotia, SP: Ateliê Editorial, 2013, p. 49-76. 
A acentuação, se recitarmos o verso sobre um tempo regular, cairá nas sílabas de número 2, 6, 10 e 12, totalizando quatro acentos. Aqui busco desvendar as nuances entre uma declamação em ritmo marcado e o canto gravado. Se atentarmos para o ritmo da melodia (os três primeiros compassos da Figura 2) desta parte da letra, notamos que as acentuações caem na tésis (tempo forte) dos dois tempos do compasso inicial, seguido da tésis do primeiro tempo do próximo compasso e da àrsis (tempo fraco ou contratempo) do segundo tempo. Pois bem, o encontro entre o recitado e o cantado se dá nos três primeiros acentos, e esse modelo é seguido na maior parte da canção, o que comprova a imbricação entre canto e fala.

Nessa chave, não há como se negar a similaridade entre "Roendo as unhas" e "Construção", ${ }^{26}$ de Chico Buarque, especialmente no que se refere à métrica dos versos, em sua maioria dodecassílabos e com acentuação idêntica. A aproximação segue no ritmo da melodia, porém com um elemento que muda o caráter das duas composições. Abaixo (Figuras 3 e 4), uma comparação entre o primeiro verso das duas canções:

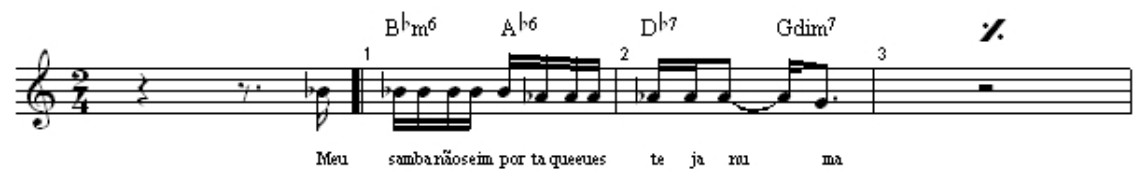

Figura 3: Primeiro verso de "Roendo as Unhas".

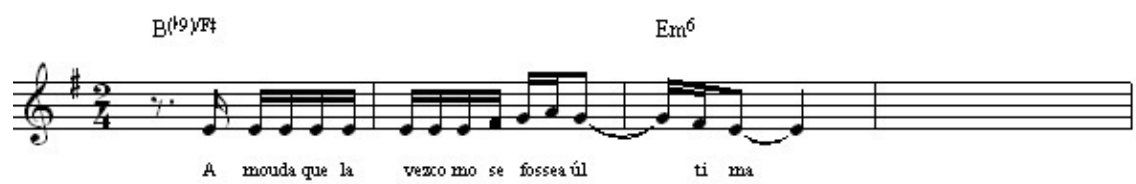

Figura 4: Primeiro verso de "Construção". 27

O ritmo e acentuação da melodia ao longo das duas composições são idênticos, à diferença da última célula rítmica dos versos, que, em

26 HOLANDA, Chico Buarque de. Construção. Construção (LP). Phonogram/Philips, 1971.

27 Deve-se levar em conta que o início da canção se localiza no acorde de Em6, sendo que as relações tonais entre tensão e repouso estão muita bem definidas, em contraponto à música de Paulinho da Viola. 
"Construção", possui uma nota a mais devido às suas bem conhecidas palavras proparoxítonas. Aqui se localiza a distinção principal: enquanto "Roendo as Unhas" inicia-se na última semicolcheia em anacruse acomodando o primeiro acento já no primeiro tempo do compasso, “Construção" realça o segundo tempo, lugar onde o surdo marca o tempo do compasso e contribui para conferir cadência ao samba.

Além disso, o que chama a atenção a partir de uma audição atenta de ambas as gravações é o caráter cíclico movido pela junção dos componentes. Como bem observado por Walter Garcia ${ }^{28}$, a história circular narrada em "Construção" e reforçada no arranjo culmina com o sufocamento do ouvinte, sendo que um desses desdobramentos seria o sentimento de indignação. Na interpretação de Nuno Ramos sobre esse mesmo tema, isso surge em decorrência da circularidade desatinada dos versos formalmente reversíveis ${ }^{29}$.

Se, para Chico, a consciência das questões materializadas numa narrativa épica leva a procurar uma saída, em Paulinho, o sujeito-liríco parece ser dotado de certa autonomia ${ }^{30}$ em relação ao tempo presente (lembramos que os verbos de "Roendo as unhas" estão baseados no presente do indicativo), aprofundando e garantindo, assim, um peso dramático e atemporal à audição em especial, à experiência histórica ali sintetizada. Noutras palavras, as duas canções dizem muito, a partir de perspectivas distintas, sobre a fase severa da ditadura militar. Uma de maneira explícita, mostrando a agonia da repetição do trabalho alienado em tempos de "milagre econômico"; e a outra, tratando de maneira introspectiva o desespero e apatia em relação à vida em tempos "de chumbo" (entre outros?). Há que se notar ainda, na minha percepção, um possível duplo sentido alcançado com a reiteração do verso "Meu samba não se importa..." seguido do prefixo condicional "se" após o verbo "importar". O primeiro sentido está ligado ao sentimento de insignificância generalizada do sujeito-samba; e o segundo, é a negação da possibilidade de importar um produto por excelência nacional (o samba) numa época da internacionalização dos mercados e de consolidação da indústria cultural no país.

28 Ainda que o assunto do autor seja a criação de um moto-contínuo em "Águas de Março", a aproximação dessa canção com a composição de Chico, sugerida no trocadilho do título e desenvolvida no artigo, nos leva a entender melhor, na minha opinião, o efeito de repetição e circularidade presente em "Construção". Ver GARCIA, Walter. A construção de “Águas de Março”. Rivista di Studi Portoghesi e Brasiliani, Pisa/Roma, n. XI, p. 39-61, 2009/2010.

29 RAMOS, Nuno. Ao redor de Paulinho da Viola, p.8z.

zo Retomo algumas ideias de Nuno Ramos. 
No âmbito do arranjo, há uma frase musical de dois compassos (Figura 3), que, localizada nos espaços de pausa do canto (Exemplos: c.3-4, 7-8, 11-12), se repete como resposta à melodia da voz. A construção da frase traz, mais uma vez, o intervalo de 5 adim., que é executado com flauta e trombone. A reiteração do trecho instrumental acentua o caráter cíclico da harmonia e contribui para acentuar a sensação de tensão.

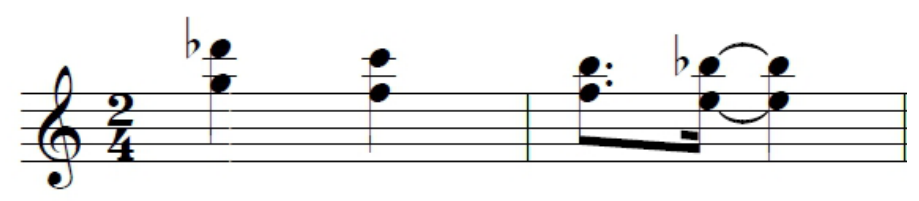

Figura 5: Frase de flauta (1 $1^{\mathrm{a}}$ voz $)$ e trombone $\left(2^{\mathrm{a}}\right.$ voz $)$.

O restante da gravação é recheado com improvisações de novas melodias que se revezam na flauta, trombone e piano, sendo que algumas vezes, durante o improviso de flauta, o trombone realiza contrapontos, num esquema similar à prática do choro. É perceptível como a base harmônica reduzida e reiterada favorece a liberdade dos instrumentos solistas e incorpora alguns procedimentos do jazz, que em grande parte de seus estilos possui improvisações de novas melodias sobre a harmonia, isto é, o centro da música se torna a harmonia em detrimento da melodia ${ }^{51}$. Vale lembrar que a sonoridade dos instrumentos, sobretudo a do trombone com surdina, conferem estranhamento às improvisações trazendo um timbre que contribui para uma estética sonora ruidosa. No universo do samba, esse recurso pode ser entendido como uma inovação, que chega até a negar a forma da canção popular brasileira consolidada nesse gênero, se materializando como uma espécie de anticanção (hegemônica).

31 Empresto aqui a ideia de Lorenzo Mammì, que se utiliza desse argumento para afirmar sobre o caráter "inútil" das improvisações sobre temas de Bossa Nova. A rigor, sua argumentação se baseia na força da melodia de Tom Jobim, muito difícil de ser substituída. O crítico ponderou esse argumento em texto posterior, adjetivando as improvisações no referido gênero como "muito tímidas" ou "meramente ornamentais". Ver MAMMİ, Lorenzo. João Gilberto e o projeto utópico da Bossa Nova. Novos Estudos Cebrap, São Paulo, n.34, p. 63-70, nov. 1992; MAMMİ, Lorenzo. Uma promessa ainda não cumprida. Folha de São Paulo, caderno "Mais", 10 de dez. de 2000. p. 6-8. No caso da gravação de "Roendo as unhas", observa-se o recurso da improvisação como uma opção estética para aprofundar o sentido de tensão despertado pela canção. 


\section{Os alicerces da tensão}

Em "Roendo as unhas", o trítono se torna um elemento vital presente nos acordes, na introdução, na distância entre as notas da melodia principal das estrofes e nas linhas melódicas do arranjo. Sua presença parece ser determinante para o sentido da canção, e dispara um estado de tensão permanente no ouvinte. Em grande parte das canções populares brasileiras, especialmente, nas composições de Paulinho da Viola, as harmonias são elaboradas dentro de um contexto tonal, situação em que o trítono serve para preparar o retorno à tônica. No samba analisado, esse intervalo não cumpre o seu papel tonal, vindo daí a sensação de tensão não resolvida.

O outro fator de convencionalização estrutural é o princípio de circularidade ocasionado pelo recurso da repetição presente em cada componente de "Roendo as unhas". Esse princípio parece traduzir musicalmente uma ideia de agonia e incerteza que atravessava o momento histórico em que foi produzida a canção. Dessa maneira, cabe esclarecer alguns elementos externos à canção.

"Roendo as unhas" foi lançada em 1973 na época de recrudescimento da ditadura militar no Brasil, precisamente cinco anos após o AI-5. Depois da tomada do poder em 1964, o governo militar foi responsável pela acentuação da desigualdade social e econômica uma vez que, dentre outros fatores, concentrou o monopólio de terra e excluiu, através da violência, a participação das forças democráticas. A partir de 1970, houve um crescimento econômico relevante (11,2\% ao ano), que trouxe significativas transformações sociais como o êxodo rural, a criação de empregos decorrentes da industrialização acelerada e uma ampliação dos sistemas de saúde e educação, que melhoraram o nível de vida apenas para uma parcela ínfima da população ${ }^{32}$.

A especificidade dessa política de Estado desembocou numa "modernização conservadora" ${ }^{33}$ para o país, sendo que a base desse processo ocorreu através de um pacto entre os representantes da velha elite dominante, ligados ao monopólio da terra, com a burguesia nacional, que, juntos, estimularam a industrialização preservando a estrutura

32 MELLO, João M. C. de; NOVAIS, Fernando A. Capitalismo tardio e sociabilidade moderna. In: SCHWARCZ, Lilia M. (org.). História da vida privada no Brasil Volume 4 (contrastes da intimidade contemporânea). São Paulo: Companhia das Letras, 20o6. p. 618-658.

33 PIRES, Murilo José de S.; RAMOS, Pedro. O termo modernização conservadora: sua origem e utilização no Brasil. Revista Econômica do Nordeste, v. 40, n. 3, p. 4,11-4,24, jul.-set. 2009 . 
fundiária. O resultado dessa união não provocou mudanças estruturais (ruptura) com o sistema anterior. Por isso, tem-se a denominação de modernização - associada ao crescimento econômico e industrial com caráter conservador - devido à ausência de mudanças estruturais no processo político.

No campo cultural, o "milagre" econômico propulsionado por uma política de internacionalização do capital se norteou por uma ideologia de integração nacional regida pelo Estado. Para os empresários, isso significou a integração de mercados, resultando em fortalecimento e consolidação de setores da indústria cultural como o editorial, o fonográfico, o da publicidade e o da televisão. Depois dos anos de 1970, o mercado fonográfico teve um crescimento vertiginoso e o long-play (LP) se consolidou como principal produto comercial da indústria da música. Os índices desse segmento de mercado superaram outros setores do entretenimento e chegaram a ultrapassar ramos da indústria têxtil, de alimentos e do vestuário ${ }^{34}$.

A concorrência entre os produtos culturais nacionais e os estrangeiros demandou um ajuste por parte dos empresários desse setor no sentido de adequar suas mercadorias a um padrão internacional, o que, no campo da música popular brasileira, se materializou em um formato de canção comercial que se realizasse como um standard internacional. Essa prática parece ter orientado, por exemplo, a concepção de alguns Festivais Internacionais da Canção (FIC) produzidos pela rede Globo de televisão depois do AI-5 ${ }^{55}$.

$\mathrm{Na}$ crítica musical produzida à época e nas análises estatísticas sobre as vendagens de discos da década de 1970, nota-se a hegemonia do samba como gênero que alcançou grande sucesso comercial no país ${ }^{36}$. Essa popularidade acarretou algumas transformações estéticas no gênero, que no plano musical se traduziram na incorporação de instrumentos como baixo, piano, teclados, bateria, cordas e sopros, ampliando-se a base consolidada pelo cavaco, pandeiro e tamborim. Nos discos de Paulinho da Viola, arranjadores mais jovens como Cristovão Bastos dividiram espaço com nomes experientes como o maestro Gaya. Em termos técnicos, ocorrera uma expressiva experimentação de timbres associada a arranjos cuidadosamente elaborados, privilegiando

34. ORTIZ, Renato. A moderna tradição brasileira: cultura brasileira e indústria cultural. São Paulo: Brasiliense, 2001, p. 118-148.

35 MACHADO, Adélcio Camilo. Quem te viu, quem te vê: o samba pede passagem para os anos 1970. 2011. 281 f. Dissertação (Mestrado em Música). Campinas: IA-Unicamp, 2011, p. 50.

36 Idem, Ibidem. 
a condução melódico-harmônica. Observa-se uma maior organização tanto da instrumentação como dos recursos de mixagem que resultou numa nova sonoridade dessa produção ${ }^{37}$.

O conjunto de informações sobre o sucesso comercial do samba nos anos 1970 aponta para novos sentidos possíveis para a trajetória desse gênero. Se nas décadas de 1930, 1940 e 1950 esteve vinculado ao projeto de construção e unificação da nação, e se nos anos 1960 esteve associado a um conteúdo revolucionário, no decênio de 1970, o gênero é ressignificado dentro do processo de internacionalização de cultura. O esmero construtivo de Paulinho da Viola, em nosso exemplo, parece apontar para uma profissionalização em todos os níveis artísticos, de sua concepção à gravação, distanciando-se de uma prática, muitas vezes, popularizada como diletante no universo do samba.

A coerência interna dos componentes que funcionam, como vimos, de maneira independente, ganha força quando entrelaçados, culminando com uma organização estrutural dotada de notável eficácia e verossimilhança. Mas, qual verdade? (em tempos de Comissão da Verdade essa pergunta parece ganhar novos significados). Possivelmente uma representação do sentido de tensão reprimido decorrente da experiência histórica ali decantada. Note-se ainda que há uma arquitetura rigorosa entre as estruturas musicais e a letra, isto é, o sentido da letra é potencializado pelo plano musical, distanciando-se de boa parte de sambas onde não há essa compatibilidade.

De volta à canção, como o título nos lembra, o ato de roer as unhas está associado a um momento de tensão ou desespero, o que refletia, num âmbito particular, a incerteza e repressão violenta da conjuntura político-social brasileira.

Sabendo-se do período sombrio da ditadura militar, a organização dos elementos da canção e suas estruturas recorrentes - o trítono e o princípio da circularidade - podem ser interpretados como um reforço da sensação de negação da vida, ou seja, um sentimento de morte que permeia a falta de perspectiva outorgada pelo Estado. Não é à toa que nesse disco de 1973 de Paulinho da Viola o protagonista do samba "Comprimido" se suicida, o que traduz a exacerbação de sentimentos de raiva e aniquilamento, que, mesmo num universo particular (na maioria das vezes em decorrência da desilusão amorosa), transbordam e soltam suas válvulas de escape dentro de um campo de tensão eminente. Nesse samba, a relação entre o sujeito e o sistema pode ser compreendida

37 TROTTA, Felipe. O samba e suas fronteiras: "pagode romântico" e "samba de raiz" nos anos 1990. Rio de Janeiro: Editora UFRJ, 2011, p. 66-67. 
de duas maneiras distintas. A primeira o coloca como vítima da situação, que, ao tomar um comprimido, sucumbe às pressões do sistema encerrando a própria vida. A outra, como um ato de redenção, ou seja, o indivíduo consciente da falta de perspectiva de sua vida comprime o sistema cometendo suicídio.

Por fim, o trítono e a ideia de circularidade, reconhecidos como dois recursos fundamentais na organização de todos os componentes em "Roendo as unhas", partem do mesmo ponto, isto é, do final interrompido da narrativa harmônica, uma espécie, talvez, de sinal fechado às possibilidades de emancipação político-social. A não-resolução do último acorde da cadência $\left(\mathrm{G}^{\circ}\right)$, ao mesmo tempo em que engendra a sensação permanente de tensão, provoca a percepção de circularidade. Essa ausência de final, também, pode estar relacionada à falta de diálogo, que lá atrás se materializava através de uma censura generalizada por parte do Estado. Passados 50 anos do golpe militar, a autonomia de "Roendo as unhas" em relação ao tempo se mostra revigorante, uma audição atenta revela, ainda hoje, um sentimento de incerteza. Dito de outra maneira: parece "que o tempo passou e não passou". ${ }^{38}$

\section{Sobre o autor}

\section{Eduardo de Lima Visconti}

Professor Adjunto de Guitarra Elétrica e Prática em Conjunto da Universidade Federal de Pernambuco (UFPE). Possui graduação em Música Popular, Mestrado e Doutorado em Música pela Universidade Estadual de Campinas (UNICAMP). Pós-doutor na área temática de Música pelo Instituto de Estudos Brasileiros (IEB) da Universidade de São Paulo (USP). E-mail: eduvisconti@yahoo.com.br

38 Cito a frase final da introdução de Roberto Schwarz ao seu ensaio sobre cultura e política nos anos de 1960. A nota introdutória (1978) foi elaborada quase dez anos depois da primeira versão. Ver SCHWARZ, Roberto. Cultura e política, 1964-1969: alguns esquemas. In: O pai de família e outros estudos. São Paulo: Companhia das Letras, 2008, p. 70 . 
